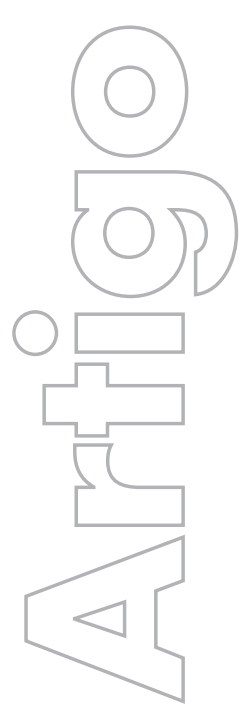

revista



espaço e tempo

Volume $23 \cdot n^{\circ} 1$ (2019)

ISSN 2179-0892

\section{Pilhagem territorial, precarização do trabalho e degradação do sujeito que trabalha: reflexões a partir da produção de celulose no Brasil}

Guilherme Marini Perpetua

Unesp e-mail: geomarini@yahoo.com.br

Antônio Thomaz Júnior Unesp e-mail: thomazjr@gmail.com

p. $124-143$

Como citar este artigo:

PERPETUA, G. M.; THOMAZ JUNIOR, A. Pilhagem territorial, precarização do trabalho e degradação do sujeito que trabalha: reflexões a partir da produção de celulose no Brasil. Geousp - Espaço e Tempo (Online), v. 23, n. 1, p. 124-143, abr. 2019. ISSN 2179-0892.

Disponível em: https://www.revistas.usp.br/geousp/article/ view/138596. doi: https://doi.org/10.11606/issn.2179-0892. geousp.2019.138596.

\section{(c) $(1) \Theta$}

Este artigo está licenciado sob a Creative Commons Attribution 4.0 License. 


\section{Pilhagem territorial, precarização do trabalho e degradação do sujeito que trabalha: reflexões a partir da produção de celulose no Brasil}

\section{Resumo}

Como resultado de uma singular combinação de fatores internos e externos, sobretudo a partir do início dos anos 2000, a economia e o território do Brasil assistiram a um extraordinário avanço da produção de commodities agropecuárias e minerais. Nesse contexto, a celulose despontou como um dos principais produtos exportados, territorializando-se em diferentes regiões por meio de megaempreendimentos que vinculam fábricas a imensas áreas de monocultivo de eucalipto. $\bigcirc$ presente artigo visa mostrar a dinâmica do trabalho no interior do recente processo de territorialização do capital arbóreo-celulósico no Brasil, com foco na precarização do trabalho e nos riscos e agravos à saúde dos trabalhadores. A pesquisa combinou procedimentos metodológicos quantitativos e qualitativos, investigando empiricamente o caso de três regiões: Porto Seguro (BA), Três Lagoas (MS) e Imperatriz (MA).

Palavras-chave: Commodities. Celulose. Precarização do trabalho. Saúde do trabalhador.

\section{Territorial looting, work precarization, and degradation of the working person: thoughts from the cellulose production in Brazil}

\footnotetext{
Abstract

As a result of singular inside and outside combination factors, particularly operating from the beginning of the 2000s, Brazil's economy and territory suffered an unheard advance in the agribusiness and mineral commodities production. In this context, the cellulose production emerged as one of the main exported products, territorializing in different regions through mega-enterprises that linked factories to huge eucalyptus monoculture areas. The objective of this paper is to unveil
} 
the working dynamic inside the recent territorialization process of the cellulosic-arboreal capital in Brazil, focusing on work precarization and on the risks and harms to the workers health. The research combined quantified and qualitative methodological procedures, investigating empirically the cases of three regions: Porto Seguro (BA), Três Lagoas (MS) e Imperatriz (MA).

Keywords: Commodities. Cellulose. Work precarization. Workers health.

\section{Introdução}

Desde o início da década de 2000, a estratégia de desenvolvimento adotada pelos governos de Luís Inácio Lula da Silva (2003-2010) e Dilma Rousseff (2011-2016) centrou parte importante de seus esforços no fomento à produção e à exportação de commodities agropecuárias (soja, carne de frango e bovina, açúcar e celulose) e minerais (minério de ferro, principalmente) altamente intensivas em recursos territoriais e com baixa agregação de valor, dispensando-lhes amplo e generoso apoio (Boito Junior, 2012). Com isso, segundo seus partidários, pretendia-se promover o crescimento econômico sustentado reduzindo, concomitantemente, a vulnerabilidade externa do balanço de pagamentos (Sicsú; Paula; Michel, 2007) por meio da geração de elevados superávits da balança comercial (Delgado, 2012). Esse tipo de argumento economicista se somou a muitos outros na construção de um consenso legitimador em torno da defesa dos "agronegócios" para o crescimento econômico e o desenvolvimento nacional. ${ }^{1}$

Não obstante, a aposta dos governos autodeclarados "progressistas" do Partido dos Trabalhadores (PT) na produção de commodities tem explicações que extrapolam as fronteiras nacionais, posto vincular-se ao fenômeno de proporções globais conhecido como superciclo das commodities (Silva, C., 2016), consubstanciado pela repentina valorização desses produtos no mercado internacional, mais expressiva no decênio 2003-2013 e fortemente alavancada pelo crescimento das importações chinesas (Contini, 2014).

$\bigcirc$ resultado da combinação das variáveis internas e externas conduziu à hegemonia do capital extrativista ${ }^{2}$ em detrimento do dinamismo industrial da economia brasileira (Petras, 2014), com o aprofundamento da lógica dependente que, como observou Marini (2011), marca nossa formação social desde o princípio. Assim, ao fortalecer seu setor primário-exportador, - Brasil promoveu um modelo de reinserção regressiva na economia mundial (Milanez, 2016).

Dois resultados diretos da adoção deste modelo foram a rápida reprimarização da pauta exportadora e o avanço dos principais monocultivos (soja, milho, cana-de-açúcar e eucalipto) (Perpetua; Gonçalves, 2017). Consolida-se, deste modo, um modelo absolutamente insustentável, quer do ponto de vista socioeconômico, quer sob a ótica ambiental. Como adverte Porto-Gonçalves (2004), sacramentando uma divisão do trabalho fundada na especialização

1 Para uma análise detalhada do assunto, ver Perpetua e Thomaz Junior (2016).

2 Na mesma linha de diversos outros autores como Gudynas (2012) e Kröger e Lalander (2016), Petras (2014) denomina extrativistas ou próprias do capitalismo extrativo não apenas as atividades extrativas de fato, como é o caso da mineração, mas, igualmente, a produção de bens primários de origem agropecuária voltados para exportação (commodities). 
dos países tropicais em gêneros básicos, mediante a constituição de agrossistemas vulneráveis altamente dependentes de insumos externos (agroquímicos), este modelo tem alto custo ecológico, econômico e político para o mundo, de forma geral, e o Brasil, em particular - veja-se, por exemplo, o vergonhoso recorde mundial de consumo de agrotóxicos, mantido desde 2008 pelo Brasil, e os dados alarmantes de conflitos por terra e água levantados pela Comissão Pastoral da Terra (2016), em franco crescimento.

Em seu bojo, a indústria de celulose mostrou-se um dos mais destacados segmentos, elevando o Brasil à condição de maior produtor de celulose de fibra curta do mundo e um dos principais produtores de árvores de rápido crescimento para finalidade industrial (Biazus, Hora; Leite, 2010a). O vertiginoso aumento da produção e da capacidade produtiva instalada se deu mediante a implantação de novos e portentosos megaempreendimentos, em diferentes pontos do território nacional, com destaque para o extremo sul da Bahia, o leste de Mato Grosso do Sul e o oeste do Maranhão.

Visando justificar o apoio irrestrito do Estado aos megaempreendimentos arbóreo-celulósicos, argumentos como os da eficiência econômica, das contribuições para a sustentabilidade ambiental e, como não poderia deixar de ser num país social e regionalmente tão desigual, da promessa de geração de milhares de empregos nos lugares onde se instalam, têm sido frequentemente evocados.

O presente texto pretende desvelar a dinâmica do trabalho no interior do recente processo de territorialização do capital arbóreo-celulósico no Brasil, com foco na precarização do trabalho e na imposição de riscos e agravos à saúde dos trabalhadores. Para tanto, a pesquisa lançou mão de procedimentos metodológicos quantitativos (levantamento e análise de dados secundários em diversos bancos) e qualitativos (realização de trabalhos de campo, observação direta e entrevistas semiestruturadas), investigando empiricamente os casos de três regiões em estados diferentes, onde, recentemente, foram implantados megaempreendimentos dessa natureza: Porto Seguro (Bahia), Três Lagoas (Mato Grosso do Sul) e Imperatriz (Maranhão). ${ }^{3}$

A tese defendida é que a estruturação atual do setor é absolutamente incompatível com o bem-estar, a segurança e a saúde dos trabalhadores envolvidos nas diversas etapas e atividades do processo produtivo considerado.

\section{A recente territorialização do capital arbóreo-celulósico no Brasil}

Tradicionalmente, a produção de papel compunha-se por etapas sucessivas e espacialmente articuladas, sendo realizada em fábricas integradas, as quais processavam a matéria-prima (madeira), transformavam-na em celulose para depois produzir o papel. Até o último quartel do século XX, os principais países produtores localizavam-se no Hemisfério Norte, com destaque para os EUA, o Canadá, a China, o Japão e os países nórdicos (Santos, 2009; Pakkasvirta, 2010). No Brasil, até os anos 1960, a indústria papeleira era incipiente, pulverizada em inúmeras empresas, importadora de grande parte de sua matéria-prima (Pedreira, 2008) e altamente concentrada nos estados do Centro-Sul, notadamente em São Paulo, mantendo-se esta última característica até o final dos anos 1990 (Daura, 2004).

3 Para finalidade estatística, adotamos o recorte microrregional proposto pelo Instituto Brasileiro de Geografia Estatística (IBGE). 
O processo de mundialização do capital (Chesnais, 1996), contudo, não deixou o setor imune, mas, ao contrário, trouxe à tona um intenso movimento de reestruturação geográfica da indústria papeleira definido pela fragmentação espacial e periferização das etapas iniciais (plantio de árvores e produção de celulose), mais custosas e socioambientalmente impactantes, rumo aos países do sul global, a exemplo do Brasil, do Chile e do Uruguai, na América do Sul; da África do Sul, do Quênia e da Nigéria, no Continente Africano; e da Indonésia, da Índia, da Tailândia e do Vietnã, na Ásia (Santos, 2009; Pakkasvirta, 2010; Morelli, 2011).

Subjacente ao novo padrão locacional da indústria celulósica está uma combinação de condicionantes repulsivos presentes nos países do norte, como a escassez de florestas nativas, as pressões ambientalistas voltadas para sua preservação e os custos mais elevados com mão de obra; e atrativos existentes no sul, como as condições edafoclimáticas favoráveis (água superficial e subterrânea abundante, solos férteis, insolação e pluviometria adequadas) refletidas na alta produtividade média da madeira, a flexibilidade da legislação ambiental e trabalhista e, não menos importante, o comprometimento dos governos locais, nos níveis nacional e subnacional, em assegurar os lucros exorbitantes das empresas do segmento a qualquer custo (Bachetta, 2008; Pakkasvirta, 2010; Morelli, 2011; Overbeek; Kröger; Gerber, 2012).

Com efeito, em sentido mais amplo esse movimento pode ser entendido como faceta específica da lógica desigual, combinada e polarizadora inerente à produção capitalista do espaço (Smith, 1988; Harvey, 2005), pois, ao se especializarem na produção e exportação de commodities como a celulose, países periféricos (ou semiperiféricos) como o Brasil assumem para si as etapas socioambientalmente mais onerosas, impactantes e com menor agregação de valor de cadeias produtivas mundializadas (Leão; Vasconcelos, 2015), funcionando como verdadeiros "nós" de uma rede de acumulação polarizada pelo norte (Kröger, 2013).

Foi nesse contexto e combinando os fatores internos e externos assinalados, que o Brasil passou a ser o maior produtor e exportador de celulose de fibra curta branqueada (BHKP, na sigla em inglês) do mundo, triplicando sua capacidade produtiva instalada (de 4,87 para 14,15 milhões t/ano) entre 1992 e 2014. Paralelamente, o plantio de árvores atingiu a marca dos 7,7 milhões de hectares em 2014 (IBA, 2015), fazendo da atividade a quarta maior em área ocupada, atrás apenas da soja, do milho e da cana-de-açúcar (IBGE, [s.d.]).

Para a efetivação deste cenário, muito contribuíram as medidas implementadas pelos governos militares, desde a década de 1960 e particularmente após o II Código Florestal Brasileiro (Lei n. 4.771/1965) e o I Plano Nacional de Papel e Celulose (PNPC), este último contido no grande arco do II Plano Nacional de Desenvolvimento (PND) (1974-1979) (Pedreira, 2008; Malina, 2013), além do vultoso aporte de recursos públicos concedidos via Banco Nacional de Desenvolvimento Econômico e Social (BNDES). ${ }^{4}$ Ao todo, entre 1955 e 2002, R\$ 30,9 bilhões (em reais de 2001) foram concedidos pelo banco, perfazendo uma média de $R$ \$1,2 bilhão por ano, sem contar as participações acionárias em diversos investimentos que também tiveram importante papel (Juvenal; Mattos, 2002). E a concessão de recursos públicos para empresas do setor pelo BNDES só aumentou nos últimos anos, somando cerca de $\mathrm{R} \$ 23,4$ bilhões apenas entre 2006 e 2013, de acordo com dados do próprio banco.

4 Para uma análise detalhada do papel do Estado brasileiro, desde os anos 1960, na constituição e no avanço do capital arbóreo-celulósico no Brasil, ver Perpetua e Thomaz Junior (2019). 
A combinação das variáveis citadas gestou um setor cujas características principais são a estrutura oligopolizadada da oferta e a verticalização do processo produtivo. Na prática, isso significa que a produção se realiza sob o comando estrito de um número muito reduzido de grandes corporações, ${ }^{5}$ as quais assumem para si todas as etapas da produção e até mesmo da circulação (Malina, 2013).

O processo de centralização do capital do setor, por seu turno, recebeu grande impulso nos anos 1990, em razão da abertura comercial e da integração competitiva e reestruturação produtiva da indústria (Pedreira, 2008; Ribeiro Junior, 2014), acompanhando a tendência mundial à oligopolização do setor. Conforme a explicação de Márcia Pedreira (2008), esse fato se deve à busca por economias técnicas de escala e pelo controle de insumos estratégicos por parte das maiores concorrentes.

Outra característica marcante da indústria de celulose no período recente é a replicação da tendência à periferização também no plano interno (Perpetua, 2013; Malina, 2013). Até o final dos anos 1990, segundo dados apresentados por Sandra Daura (2004), a produção de celulose encontrava-se extremamente concentrada do ponto de vista geográfico, correspondendo à região Sudeste sozinha 57\% e ao Sul 30\% de toda a produção nacional. A mudança no padrão locacional foi de tal envergadura que, atualmente, quase todas as plantas fabris de celulose instaladas, em instalação ou previstas localizam-se (ou pretendem localizar-se) em estados do Centro-Oeste, do Nordeste e do Norte do país. Os motivos não são outros quando comparados ao movimento desdobrado em escala mundial: busca por redução de custos com a compra de terras, exploração de condições edafoclimáticas mais favoráveis, maior facilidade para burlar as legislações ambiental e trabalhista, mão de obra barata e menos organizada, inexistência ou incipiência de movimentos sociais e, não menos importante, aproveitamento dos generosos "incentivos" oferecidos por estados e municípios mais afastados da core area nacional (Perpetua, 2013).

Desse modo, nos últimos anos, o Brasil tem levado adiante a opção pela especialização regressiva, tendo por loci espaços regionais receptores de grandes inversões que os tornam altamente especializados. Sem dúvida, os principais exemplos são o extremo sul da Bahia (microrregião de Porto Seguro), onde se situa, desde 2005, a fábrica da transnacional Veracel Celulose, joint venture entre a brasileira Fibria e sueco-finlandesa Stora Enso; a região de Três Lagoas, leste de Mato Grosso do Sul, onde se encontram os empreendimentos da Fibria Celulose e da Eldorado Brasil, respectivamente inaugurados em 2009 e 2012 e atualmente em processo de ampliação; e a região de Imperatriz, no oeste do Maranhão, lugar onde a Suzano implantou sua mais nova fábrica, em 2013, em plena Mata dos Cocais.

\section{Trabalho escasso, malremunerado e volátil}

Todo e qualquer anúncio de implantação de uma nova fábrica de celulose veiculado traz uma estimativa superdimensionada do número de empregos a ser gerado. Sem entrar nos pormenores acerca da natureza dos empregos, os escribas da comunicação procuram deslumbrar

5 Em 2008, conforme Biazus, Hora e Leite (2010a), 84,7\% da capacidade produtiva instalada nacional estava nas mãos de apenas sete empresas: Fibria, Suzano Papel e Celulose, Klabin, Cenibra, International Paper, Veracel Celulose e Jari Celulose. A partir de 2010, a Eldorado Brasil Celulose somou-se a esse seleto grupo. 
os espectadores com os milhares de postos de trabalho, "entre diretos, indiretos e por efeito renda", exaltando suas virtudes na transformação das regiões "degradadas" e "abandonadas" do interior. Na realidade, porém, como advertem Souza e Overbeek (2008, p. 56), "nas regiões onde é plantada a monocultura de eucalipto e produzida a celulose, é amplamente sabido que essas atividades contribuem pouco para a geração de empregos".

Isso se torna patente quando comparamos os dados relativos às admissões nas atividades envolvidas no processo de produção da celulose ${ }^{6} \mathrm{com}$ o total de admissões nos três municípios-sede dos empreendimentos estudados (Tabela 1), nos quais, como pudemos constatar por ocasião dos trabalhos de campo realizados, a atividade apresentou-se como "carro-chefe" e "tábua de salvação" perante a sociedade local.

Tabela 1 - Trabalhadores admitidos em atividades ligadas à produção de celulose em relação ao total de admissões em Eunápolis (BA), Três Lagoas (MS) e Imperatriz (MA) - 2007-2013

\begin{tabular}{|l|l|l|l|l|l|l|l|}
\hline & $\begin{array}{l}\text { produção } \\
\text { de mudas } \\
\text { e outras } \\
\text { formas de } \\
\text { propaga- } \\
\text { ção vege- } \\
\text { tal certifi- } \\
\text { cadas }\end{array}$ & $\begin{array}{l}\text { produção } \\
\text { florestal - } \\
\text { florestas } \\
\text { plantadas }\end{array}$ & $\begin{array}{l}\text { ativida- } \\
\text { des de } \\
\text { apoio à } \\
\text { produção } \\
\text { florestal }\end{array}$ & $\begin{array}{l}\text { fabrica- } \\
\text { ção de } \\
\text { celulose } \\
\text { e outras } \\
\text { pastas } \\
\text { para a fa- } \\
\text { bricação } \\
\text { de papel }\end{array}$ & $\begin{array}{l}\text { total de } \\
\text { admissões } \\
\text { (ativida- } \\
\text { des sele- } \\
\text { cionadas) }\end{array}$ & $\begin{array}{l}\text { total de } \\
\text { admissões } \\
\text { (todas as } \\
\text { ativida- } \\
\text { des) }\end{array}$ & var.\% \\
\hline 2007 & 0 & 117 & 1.667 & 54 & 1.852 & 30.731 & 6,02 \\
\hline 2008 & 11 & 773 & 2.106 & 386 & 3.276 & 42.432 & 7,72 \\
\hline 2009 & 0 & 307 & 2.165 & 108 & 2.580 & 34.737 & 7,42 \\
\hline 2010 & 0 & 397 & 3.106 & 196 & 3.699 & 42.620 & 8,67 \\
\hline 2011 & 2 & 1.256 & 5.061 & 398 & 5.595 & 52.118 & 10,73 \\
\hline 2012 & 0 & 1.269 & 2.733 & 589 & 4.591 & 59.058 & 7,77 \\
\hline 2013 & 0 & 1.657 & 2.387 & 643 & 4.687 & 70.573 & 6,64 \\
\hline total & 13 & 5.776 & 19.225 & 2.374 & 26.280 & 332.269 & 7,9 \\
\hline
\end{tabular}

fonte: Brasil ([s.d.]). elaboração: Os autores.

Considerando o volume de investimentos requerido ( $R \$ 3,4$ bilhões para o projeto da Veracel na Bahia; $\mathrm{R} \$ 3,88$ e $\mathrm{R} \$ 5,1$ bilhões, respectivamente, para os projetos da Fibria e Eldorado Brasil em Três Lagoas; e cerca de $\mathrm{R} \$ 5$ bilhões para o projeto da Suzano em Imperatriz) e a intensa especialização econômica regional acarretada, salta aos olhos a pequena proporção ocupada pelos empregos gerados nas atividades do segmento arbóreo-celulósico, em relação à média do total de admissões (7,9\%). Ademais, o número de admissões apresenta intermi-

6 Os dados sobre emprego foram coletados na Classificação Nacional de Atividades Econômicas (Cnae), em sua versão 2.0, nos extratos Setor e Classe. 
tência, com picos e períodos de retração, havendo ainda enorme predomínio dos empregos gerados nas "atividades de apoio à produção florestal", normalmente demandantes de pouco preparo técnico e pior remuneradas.

A efervescência da geração de empregos alardeada pelas empresas e seus porta-vozes limita-se à fase de construção e montagem das unidades fabris, habitualmente prolongada por um período que não excede dois anos e abastecida por uma mão de obra predominantemente composta por trabalhadores migrantes - os "peões do trecho", como são conhecidos -, os quais acompanham as empreiteiras subcontratadas em obras em diversos pontos do país (Perpetua, 2013). Após entrar em operação, uma fábrica moderna de celulose não necessita de mais do que três ou quatro centenas de trabalhadores para o seu funcionamento,? um cenário que não destoa muito daquele encontrado nas atividades de silvicultura (preparo do solo, plantio, manejo, corte e transporte de árvores), para as quais algumas fontes chegam a calcular a geração de apenas um emprego direto para cada 187 ha ocupados ( $\bigcirc$ eucalipto [...], 2012). A escassez de empregos é, portanto, uma marca característica desse tipo de empreendimento.

É fato que o número de empregos nas atividades do setor como um todo vem caindo drástica e continuamente desde os anos 1970 (De'Nadai; Soares; Overbeek, 2011), fenômeno intensificado pelo "ajuste" neoliberal da década de 1990 (Daura, 2004). Na base dessa transformação estão modificações gerenciais (enxugamento ou liofilização organizacional) e, sobretudo, processos de automação industrial e mecanização das atividades agrícolas, por meio da introdução de máquinas e implementos poupadores de trabalho vivo.

Mas os problemas não param por aí. Muitos dos postos de trabalho efetivamente gerados, em especial os melhor remunerados, são ocupados por trabalhadores migrantes provenientes de outras regiões, a grande maioria já empregada pelas mesmas ou por outras empresas, em busca de melhores salários e condições de vida. ${ }^{.}$Destaque-se ainda o fato de que a escassez do trabalho vivo se relaciona também, e principalmente, com a eliminação de inúmeros empregos em outras atividades. Isso ocorre porque um dos desdobramentos indiretos da expansão do monocultivo do eucalipto é a expulsão de trabalhadores (camponeses, agregados das fazendas, trabalhadores da pecuária etc.) do campo, engrossando as fileiras do êxodo rural em direção às periferias urbanas (Koopmans, 2005; Pedreira, 2008; Kudlavicz, 2011). Em muitos casos, os mesmos sujeitos outrora expulsos retornam à terra, mas dessa vez para ocupá-la em nome da efetividade de uma reforma agrária cada vez mais distante.

Daí também a retração da produção de alimentos ser um dos principais sintomas do avanço da monocultura arbórea, resultando na eliminação de postos de trabalho no campo. Vale lembrar que, no Brasil, a agricultura camponesa é a principal responsável pela atividade, respondendo por pelo menos 70\% de todos os alimentos produzidos. ${ }^{9}$ Segundo dados da Produção Agrícola Municipal (IBGE, [s.d.]), na região de Porto Seguro (BA), a área ocupada com os principais cultivos alimentares foi reduzida em 36,9\% (17.885 ha), entre 2000 e 2010. Na região de Imperatriz (MA), a retração foi da ordem de 54,1\% (15.797 ha) no mesmo período,

7 Informação verbal fornecida em entrevista com técnico de empresa realizada em 16 de dezembro de 2014 em Três Lagoas (MS).

8 Informações verbais fornecidas em entrevistas realizadas nos meses de março, setembro, novembro e dezembro de 2014.

9 Dados oficiais disponibilizados pelo governo brasileiro estimaram em 70\% a participação da agricultura familiar na produção de alimentos na safra 2015-2016 (Agricultura..., 2015). 
tendo sido puxada pelo arroz, cultivo tradicional da região. Já na região de Três Lagoas, a redução do efetivo bovino em mais de 632 mil cabeças superou a perda provocada pela retração da área voltada para a produção de alimentos, a qual, de todo modo, não deixou de ser expressiva (32,3\% ou 5.835 ha entre 2001, período de pico, e 2010).

A baixa remuneração é outra característica dos empregos gerados nas atividades em tela (Gráfico 1).

Gráfico 1 - Faixa de salário mensal nas atividades relativas à produção de celulose nas regiões estudadas - 2013

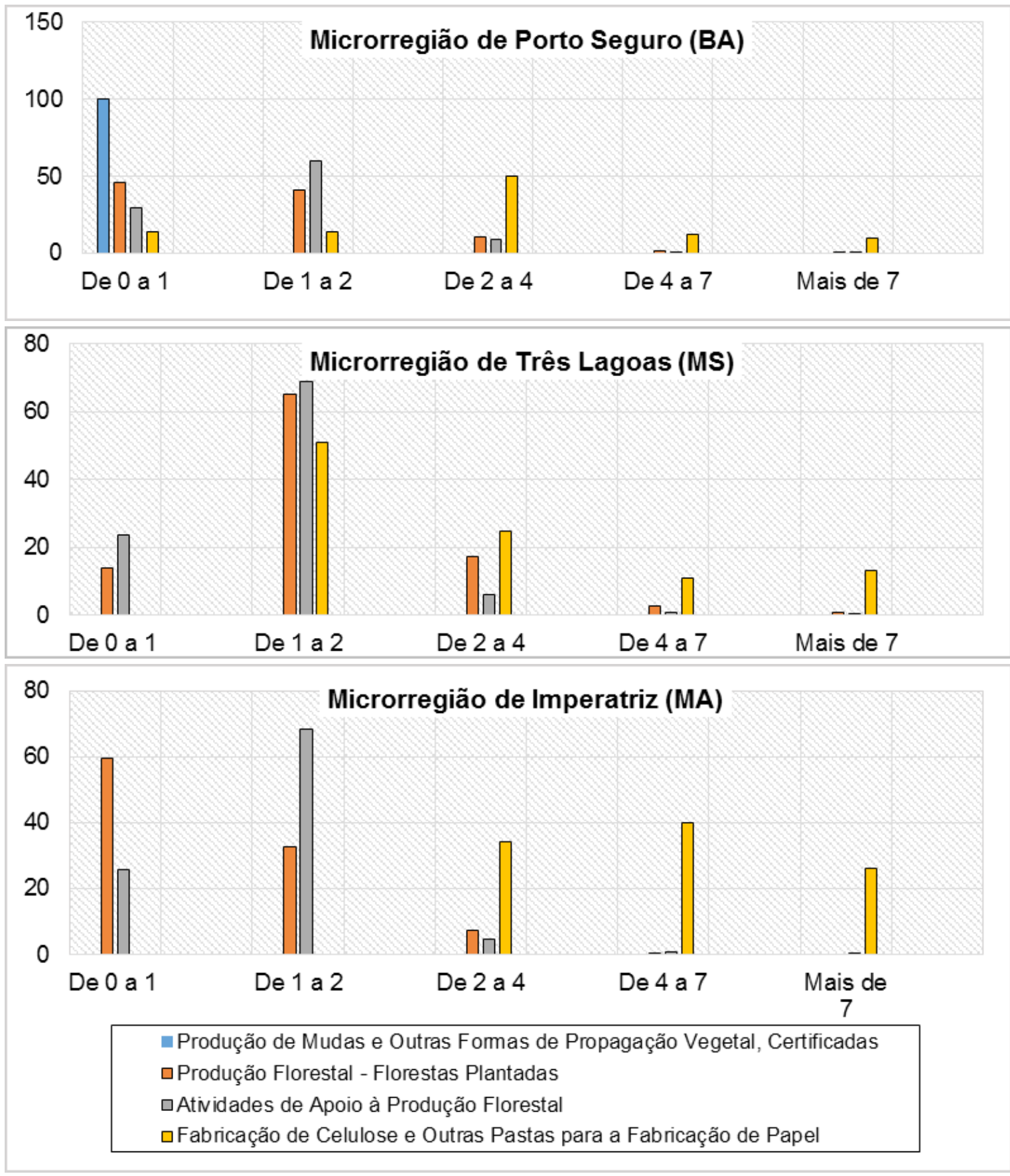

fonte: Brasil ([s.d.]). elaboração: Os autores. 
Nas atividades de "produção de mudas e outras formas de propagação vegetal, certificadas", "produção florestal - florestas plantadas" e "atividades de apoio à produção florestal", a esmagadora maioria dos empregados concentra-se na faixa de até 2 salários-mínimos, havendo certa variação entre Porto Seguro (pior situação) e Três Lagoas (melhor situação). Entre todas, a atividade de "fabricação de celulose e outras pastas para a fabricação de papel" é a exceção, apresentando maior percentual de empregados nas faixas acima de dois salários-mínimos. Convém lembrar, entretanto, que essa atividade é a que menos absorve mão de obra (Tabela 1).

Por fim, outra entre as principais feições do segmento produtivo estudado é a alta rotatividade (turnover) da mão de obra (Gráfico 2).

\section{Gráfico 2 - Admissões e desligamentos nas atividades relacionadas à pro- dução de celulose nas regiões estudadas - 2007-2014}


fonte: Brasil ([s.d.]). elaboração: Os autores. 
Reproduzindo o padrão nacional para as atividades selecionadas, nas regiões de Porto Seguro, Três Lagoas e Imperatriz, entre 2007 e 2014 (Gráfico 2), quando não ultrapassa, o número de desligamentos beira o de admissões, demonstrando que grande parte dos supostos empregos gerados na verdade, quando muito, repõe empregos eliminados.

Para dirimir qualquer dúvida quanto aos motivos dos desligamentos massivos observados, importa mencionar que, em média, nas regiões e atividades analisadas, 77,2\% deles ocorreram por demissão sem justa causa e término de contrato, isto é, por motivos independentes da vontade dos trabalhadores.

Baixa geração de empregos, empregos malremunerados e altamente rotativos: eis apenas a superfície do problemático círculo de aspectos que encerra os trabalhadores na produção de celulose.

\section{Territorialização, precarização, riscos e agravos à saúde dos trabalhadores}

Muito além de aspectos constatados por meio dos dados sobre renda, admissões e desligamentos disponibilizados pelo Cadastro Geral de Empregados e Desempregados - Caged (Brasil, [s.d.]), a análise do recente processo de territorialização do capital arbóreo-celulósico no Brasil revela a marca da precarização, condição potencializadora da imposição de riscos e agravos à saúde dos trabalhadores.

As transformações econômicas, políticas, técnicas e organizacionais que caracterizam a reestruturação produtiva do capital em escala mundial, a partir dos anos 1970, e suas implicações no tocante à constituição do regime de acumulação flexível rebateram duramente sobre os trabalhadores numa plêiade de desdobramentos denominada por muitos estudiosos precarização do trabalho (Mattoso, 1995; Antunes, 1999; Alves, 2000; Druck, 2011). Conforme Mattoso (1995), em termos geris, esse conceito faz referência ao processo amplo e variado de mudanças nas condições de trabalho, no mercado de trabalho, nas exigências de qualificação dos trabalhadores e nos direitos trabalhistas engendrado no interior da crise do regime fordista e emergência do regime toyotista ou flexível.

No Brasil, os novos elementos "flexíveis" de cariz toyotista só foram introduzidos de forma sistêmica a partir dos anos 1990 (Alves, 2000), mas sem promover nenhuma homogeneização entre setores produtivos, regiões ou mesmo empresas (Thomaz Junior, 2012). Na realidade, o que houve foi a combinação entre regimes produtivos e suas formas de organização e controle do trabalho, colocando vis-à-vis elementos regressivos e espectrais e agravando ainda mais as já (e desde sempre) precárias condições e relações de trabalho (Alves, 2002/2003).

Mesmo limitada por características específicas das indústrias de processo contínuo, como é o caso da de celulose, a reestruturação tornou-se a pedra de toque e foi maciçamente incorporada pelas empresas durante a fase neoliberal. As novas rotinas, formas de contratação, remuneração e controle flexíveis oriundas do novo regime de acumulação varreram o setor de norte a sul e de leste a oeste, ao lado da tendência geral de redução da mão de obra empregada.

Para os propósitos deste artigo, recorremos à distinção feita por Alves (2011) quanto às três formas assumidas pelo fenômeno da flexibilização, principal veículo da precarização do trabalho: a flexibilização da contratação, da jornada e da remuneração. 
Sem dúvida, um dos traços mais emblemáticos do trabalho no complexo arbóreo-celulósico é a terceirização generalizada, a qual atingia quase $70 \%$ da mão de obra empregada nas empresas estudadas, em 2013 (Tabela 2).

\section{Tabela 2 - Tipo de vínculo de trabalho nas empresas produtoras de celu- lose -2013}

\begin{tabular}{|l|l|l|l|l|l|}
\hline empresas/funcionários & próprios & $\%$ & terceirizados & $\%$ & total \\
\hline Veracel Celulose & 701 & 16,42 & 3.567 & 83,58 & 4.268 \\
\hline Eldorado Brasil & 2.218 & 51,01 & 2.130 & 48,99 & 4.348 \\
\hline Suzano Papel e Celulose & 6.409 & 38,28 & 10.330 & 61,72 & 16.739 \\
\hline Fibria Celulose & 3.827 & 22,28 & 13.343 & 77,07 & 17.170 \\
\hline total & 13.155 & $\mathbf{3 0 , 9 3}$ & $\mathbf{2 9 . 3 7 0}$ & $\mathbf{6 9 , 0 7}$ & $\mathbf{4 2 . 5 2 5}$ \\
\hline
\end{tabular}

fonte: Veracel (2013); Suzano (2012); Eldorado Brasil (2013); Fibria (2013). elaboração: Os autores.

Conforme Leite, Souza e Machado (2002 ${ }^{10}$ apud Oliveira, 2014, p. 215), "o processo de terceirização no setor de eucalipto-celulose-papel tem sido crescente, expandindo-se estrategicamente para quase todos os subsetores das atividades envolvendo o monocultivo de eucalipto e fabricação de celulose e papel.".

Malgrado as alegações centradas nos benefícios decorrentes da especialização empresarial em determinados tipos de produtos/serviços, são amplamente mensurados e conhecidos os efeitos deletérios da terceirização em relação às condições e à jornada de trabalho, à remuneração, à resistência e identidade de classe, bem como à segurança e à saúde dos trabalhadores (Dieese, 2007; Druck, 2011).

Os trabalhos de campo e entrevistas realizadas permitiram constatar que, neste segmento produtivo específico, a terceirização disseminou-se mais amplamente entre as atividades de campo, ligadas ao fornecimento de matéria-prima, mais profusas em mão de obra e com piores condições de trabalho, remuneração e jornada. Em muitos casos, constatou-se um processo de "subcontratação em cascata", isto é, envolvendo três, quatro, cinco ou mais empresas direta ou indiretamente vinculadas à tomadora de serviço. Todavia, cabe ressalvar que mesmo no campo há algumas funções para as quais as empresas preferem a contratação direta, como é o caso dos cargos de supervisão, chefia, saúde ocupacional e segurança do trabalho.

No caso do cultivo de eucalipto para produção de celulose, diferentemente de outros cultivos e atividades, via de regra, as áreas de plantio encontram-se espacialmente integradas às fábricas, espalhando-se os eucaliptais a partir delas, principalmente em função da alta proporção ocupada pelos custos com madeira e transporte no cômputo geral dos custos produtivos desta commodity. Assim, a localização da indústria é ditada pela localização das fontes de matéria-prima (Biazus; Hora; Leite, 2010b). Disso resulta um arranjo territorial extremamente funcional aos objetivos do capital composto por hierarquias superpostas entre a contratante e

10 LEITE, A. M. P.; SOUZA, A. P.; MACHADO, C. C. Terceirização. In: MACHADO, C. C. (Coord.). Colheita

florestal. Viçosa, MG: UFV, 2002. p. 423-444. 
as subcontratadas, o qual está na base de outros elementos da precarização e, por conseguinte, da imposição de riscos e agravos à saúde dos trabalhadores. Ao terceirizar, as chamadas empresas-mãe transferem toda a responsabilidade pelos trabalhadores às subcontratadas, pagando não mais pela produção, mas por um serviço, e impondo às "parceiras" metas superdimensionadas de fornecimento que devem ser cumpridas segundo orientações precisas e extremamente rígidas quanto aos padrões de qualidade do produto, meio ambiente e trabalho. Objetivando vencer a concorrência e firmar os contratos, as prestadoras de serviço subcontratadas, por sua vez, procuram intensificar a produção e reduzir cada vez mais os custos, amplificando as exigências e rebaixando ao extremo as condições de trabalho.

O controle do tempo de trabalho foi, desde sempre, conditio sine qua non da acumulação do capital. Sob o imperativo da contabilidade capitalista do tempo (Mészáros, 2007), os seres humanos perdem suas particularidades, homogeneizados na estreita medida do trabalho abstrato (trabalho indiferente, simples tempo de trabalho socialmente necessário); em uma palavra, como afirmou Marx (2009), tornam-se, quando muito, "carcaça do tempo".

$\bigcirc$ controle capitalista do tempo de trabalho assume duas dimensões distintas e, em geral, conciliadas: o controle da duração, isto é, da extensão da jornada de trabalho, permitindo a extração de excedente na forma de mais-valor absoluto; e o controle do ritmo ou intensidade do trabalho, por intermédio de incrementos técnicos e organizacionais na produção capazes de impor a extração de mais-valor relativo (Marx, 2013). Não são outros os ingredientes da receita de flexibilização e precarização, por meio do controle do tempo de trabalho, na produção de celulose.

$\bigcirc$ trabalho por turnos alternados e as longas jornadas são elementos comuns, tanto nas áreas de cultivo, quanto nas fábricas. No campo, segundo depoimentos dos trabalhadores, a jornada de trabalho estende-se comumente por 13, 14 e até 15 horas seguidas, somado o tempo de deslocamento até os hortos (locais de plantio, trato ou corte do eucalipto), a depender de sua localização. Conforme outros trabalhadores entrevistados, nas empresas terceirizadas do campo normalmente a jornada costuma ser mais extensa, sendo essa mais uma entre as evidências da precarização do trabalho atuando em conjunto, por exemplo, com as condições de transporte inadequadas e o desgaste físico inerente às próprias atividades, ocasionado pelo intenso ritmo de trabalho sob forte interferência das intempéries (calor, frio, chuva, vento etc.).

Entre os operadores de máquinas agrícolas de corte e transporte ocorre algo muito semelhante. A atividade propriamente dita estende-se por 8 horas diárias, em sistema de turnos que não excluem a possibilidade da realização de muitas horas extras. Porém, por conta da distância dos locais de trabalho, a jornada pode ter início horas antes e findar muito depois. E mesmo ficando à disposição da empresa por pelo menos quatro horas adicionais todos os dias, os trabalhadores recebem apenas por um número simbólico das chamadas horas in itinere, as quais deveriam corresponder à totalidade do tempo de deslocamento. Outrossim, adequar o relógio biológico às inconstâncias da relação entre tempo de trabalho e tempo de vida, o primeiro invadindo cada vez mais os limites do segundo, constitui um enorme desafio à saúde dos trabalhadores.

Sistematicamente, as empresas têm combinado às extensas jornadas diversos expedientes tipicamente flexíveis para elevar o ritmo de trabalho e extrair mais-valor relativo. $\bigcirc$ principal deles é o sistema de metas de produção, normalmente associado, de um lado, à remuneração variável (bônus e prêmios por produção) e, de outro, a penalizações as mais diversas. 
Visando cumprir as metas superdimensionadas de modo a receber a remuneração supostamente adicional - que, na verdade, constitui parte significativa do salário -, prepostos das empresas soem encurtar os intervalos entre tarefas, jornadas e até mesmo pausas para descanso e atendimento de necessidades fisiológicas dos trabalhadores. No campo, o ritmo de trabalho é ditado pelas metas de plantio e corte estabelecidas e monitoradas diuturnamente pelas empresas-mãe, que, por sua vez, devem adequar-se à demanda do mercado externo, regulada pelos contratos firmados junto aos compradores. Cabe esclarecer que as metas impostas aos trabalhadores não são individuais e sim coletivas, potencializando ainda mais o controle verticalizado por meio da pressão exercida entre os próprios trabalhadores, uns sobre os outros.

Em suma, o capital, essa estrutura totalizadora de controle do metabolismo social (Mészáros, 2011), só controla o território ao controlar o trabalho, e só pode controlar o trabaIho por meio da constituição e manutenção de frações de espaço definidas e delimitadas por relações de poder cujo fim precípuo é a acumulação ampliada. $\bigcirc$ resultado, obviamente, não poderia ser outro: ambientes de trabalho repletos de agentes de risco potencialmente geradores de agravos os mais diversos à saúde dos trabalhadores.

Corroborando a absurda estatística nacional de agravos decorrentes do trabalho, ${ }^{11}$ a indústria de celulose, papel e produtos de papel ocupava, em 2004, o décimo lugar no ranking de setores industriais com maiores taxas de acidente de trabalho: 32,5/1.000 trabalhadores (Silva, M. et al., 2011). De acordo com dados do Ministério da Previdência Social, entre 2007 e 2013, houve 29.736 casos de acidente (típicos e de trajeto) e adoecimento no trabalho nas atividades relativas à produção de celulose no Brasil.

Conquanto constitua uma evidência concreta da degradação do trabalho nas atividades e regiões estudadas, a análise quantitativa deve ser tomada apenas como indício de uma realidade muito mais grave e pouco aclarada, em função da desmesurada subnotificação que impera nos sistemas de registro, no Brasil (Binder; Cordeiro, 2003; Lourenço, 2011). Os dados secundários também não podem revelar as formas de organização, as condições de trabalho e sua intervenção no processo de trabalho, como conjunto de agentes de risco potencialmente geradores de agravos à saúde (Agostini, 2002), uma vez que, conforme Binder e Cordeiro (2003, p. 410, grifos nossos), "acidentes de trabalho são fenômenos socialmente determinados, indicativos da intensa exploração a que é submetida grande parte dos trabalhadores".

Nesse sentido, a pesquisa qualitativa permitiu constatar que as diversas atividades/funções constitutivas do processo produtivo estão povoadas de agentes de riscos, os quais são fortemente incrementados pelas formas flexíveis de organização e controle da força de trabalho anteriormente explicitadas. Entre eles, destacam-se os riscos físicos (incêndio nos eucaliptais, acidentes durante o transporte, quedas, torções de membros, mutilações durante o manuseio de ferramentas e/ou em contato com o ambiente de trabalho, choques elétricos por cabos de alta voltagem, lesões por esforço repetitivo etc.) e químicos (intoxicação por contato direto ou indireto com agrotóxicos e/ou substâncias empregadas no processo industrial). Muitos dos

11 Segundo estudo da Central Única dos Trabalhadores (CUT) divulgado pela Rede Brasil Atual em 9 de maio de 2014, entre 1990 e 2012, ocorreram 4.116.599 acidentes, 127.535 casos de adoecimento e 23.604 mortes em decorrência do trabalho no Brasil. De janeiro de 2012 a janeiro de 2019, foram registrados pouco mais de 4,5 milhões de acidentes e 16,9 mil mortes em decorrência do trabalho, tendo a Previdência Social desembolsado cerca de R \$ 78,3 bilhões para o pagamento de benefícios acidentários (Observatório Digital de Saúde e Segurança do Trabalho, [2017?]). 
trabalhadores entrevistados elencaram tais riscos e relataram ter conhecimento e mesmo haver sofrido algum tipo de acidente ou doença em função da atividade exercida, como se vê nas transcrições a seguir, excertos das entrevistas realizadas em campo:

Às vezes, no campo, tem muita área "suja", [onde o trabalhador] tropeça, pode tropeçar. Tem lugar que tem buraco em área que a gente pisa e não está vendo; aí, a gente fica sujeito [a se acidentar] também. A irrigação é uma operação que tem muito perigo, porque na estrada que está em reforma tem muito "pauzeiro" dos que cortam. Quando o trator vai passando, vai levantando ponta de pau. É um risco muito grande para o pessoal que vai irrigando, porque o trator vai puxando a pipa, e o cara do lado, aqui. Se não for com muita atenção, acontece acidente (Trabalhador terceirizado do plantio na Suzano de Imperatriz, 13 set. 2014).

Nós temos o Rafer lá. O Rafer, para uma pessoa ver você trabalhar, ela tem que ficar a uma distância de, no mínimo, cem metros. Por quê? Porque ele tem elos de corrente, corrente de motosserra; se aquilo lá estoura, voa que nem uma bala até cem metros e, se bater [em alguém], pode até matar uma pessoa. Então, é segurança total. Teve um caso que aconteceu e nós ficamos sabendo de um rapaz que abriu a porta, segurou a trava de segurança e foi operar para mostrar para o mecânico. Estourou um elo daquele, e ele está lá, alojado no rosto dele até hoje (Operador da fibria em Três Lagoas, 26 nov. 2014).

Não obstante, as empresas continuam apostando amplamente em soluções unicausais e individualizadas, como o uso dos equipamentos de proteção individual (EPI) e o estabelecimento de programas de segurança no trabalho compostos por uma infinidade de regras de conduta coletivamente fiscalizadas. Estas, por sua vez, são transformadas em metas cuja "não observância" conduz à redução do salário e até mesmo à demissão.

Com isso, a culpa pelos agravos recai sempre sobre os próprios trabalhadores, acusados ora por "desatenção", ora por "irresponsabilidade" ou "comportamento imprudente" ou "inseguro", ocultando-se, assim, o processo degradante de trabalho a que esses sujeitos estão submetidos nos territórios do capital. Tampouco nesse particular há novidade, pois, como afirmam Vilela, Iguti e Almeida (2004, p. 571), no Brasil como no mundo predomina uma compreensão simplista, monocausal, linear e determinística de acidente, cuja abordagem privilegia o entendimento de que "[...] os acidentes decorrem de falhas dos operadores (ações ou omissões), de intervenções em que ocorre desrespeito à norma ou prescrição de segurança, enfim, 'atos inseguros' originados em aspectos psicológicos dos trabalhadores".

\section{Considerações finais}

Pela análise da dinâmica do trabalho no interior da territorialização de um segmento produtivo específico (produção de celulose), procuramos demonstrar o caráter farsesco que revestiu os megaempreendimentos do capital envolvidos na produção de commodities agrominerais no Brasil, sob a vigência do novo desenvolvimentismo. Por sua forma de inserção no mercado internacional e suas próprias características intrínsecas, a indústria de celulose tem procurado se aproveitar ao máximo de "vantagens territoriais", ao mesmo tempo em que rebaixa custos pro- 
dutivos, destacadamente o do trabalho vivo. Assim, não se pode negar que se gerem empregos, mas eles são escassas, malremunerados e voláteis. $\bigcirc$ trabalho nas atividades estudadas revela-se, sobretudo, extremamente precário e degradante para os seres humanos, cujo esfalfante esforço gera a riqueza de que se jactam os representantes do capital e do Estado.

Porém, para compreender as formas de organização e controle do trabalho, as condições a que estão submetidos trabalhadoras e trabalhadores envolvidos direta ou indiretamente na produção de celulose e seus rebatimentos no tocante aos riscos e agravos à saúde, foi necessário ir muito além da mera aparência fenomênica. Em síntese, a partir da perspectiva dialético-materialista da totalidade, procuramos estabelecer os principais nexos e categoriais entre a produção de celulose no Brasil, a forma de inserção do país na divisão internacional do trabalho, intimamente ligada ao processo histórico de estruturação interna desse segmento, e as marcas nem sempre visíveis da precarização e da degradação dos sujeitos que trabalham.

Adotando o conceito de território, mostramos que os novos megaempreendimentos estudados só se viabilizam pela imposição vertical de formas de controle que pressionam os recursos territoriais, entre os quais os próprios seres humanos, muito além de qualquer limite aceitável. Não obstante suas especificidades, infelizmente, esse não é um caso isolado, senão apenas uma das muitas expressões particulares da irracionalidade sistêmica, incontrolável e essencialmente destrutiva do capital em tempos de crise estrutural.

\section{Referências}

ABRAF. ASSOCIAÇÃO BRASILEIRA DE PRODUTORES DE FLORESTAS PLANTADAS. Anuário estatístico Abraf 2013: ano base 2012. Brasilia, DF: Abraf, 2013.

AGOSTINI, M. Saúde do trabalhador. In: ANDRADE, A.; PINTO, S. C.; OLIVEIRA, R. S. (Org.). Animais de laboratório: criação e experimentação [on-line]. Rio de Janeiro: Ed. Fiocruz, 2002. p. 375-379.

AGRICULTURA familiar produz 70\% dos alimentos consumidos por brasileiro. Brasília, DF: 24 jul. 2015. Disponível em: http://www.brasil.gov.br/economia-e-emprego/2015/07/ agricultura-familiar-produz-70-dos-alimentos-consumidos-por-brasileiro. Acesso em: 31 jul. 2017.

ALVES, G. Trabalho flexível, vida reduzida e precarização do homem-que-trabalha: perspectivas do capitalismo global no século XXI. In: VIZZACCARO-AMARAL, A. L.; MOTA, D. P.; ALVES, G. (Org.). Trabalho e saúde: a precarização do trabalho e a saúde do trabalhador no século XXI. São Paulo: LTr, 2011. p. 39-55.

ALVES, G. Globalização como processo civilizatório humano-genérico. Estudos de Sociologia, Araraquara, n. 13/14, p. 37-48, 2002/2003.

ALVES, G. $\mathbf{O}$ novo (e precário) mundo do trabalho: reestruturação produtiva e crise do sindicalismo. São Paulo: Boitempo, 2000. 
ANTUNES, R. Os sentidos do trabalho: ensaios sobre a afirmação e a negação do trabaIho. São Paulo: Boitempo, 1999.

BACHETTA, V. La fraude de la celulosa. Montevideo: Doble Clic, 2008.

BIAZUS, A.; HORA, A. B.; LEITE, B. G. P. Panorama de mercado: celulose. BNDES Setorial, São Paulo, n. 32, p. 311-370, 2010a.

BIAZUS, A.; HORA, A. B.; LEITE, B. G. P. Papel e celulose: perspectivas de investimento 2010-2013. São Paulo: BNDES, 2010b.

BINDER, M. C. P.; CORDEIRO, R. Sub-registro de acidentes de trabalho em localidades do estado de São Paulo. Revista de Saúde Pública, São Paulo: FSP-USP, v. 4, n. 37, p. 409-416, 2003.

BOITO JUNIOR, A. As bases políticas do neodesenvolvimentismo. Fórum Econômico Da FGV, 2012, São Paulo. Anais... São Paulo: FGV, 2012.

BRASIL. Ministério do Trabalho e Emprego. Cadastro Geral de Empregados e Desempregados - Caged. Disponível em: http://bi.mte.gov.br/bgproger/. Acesso em:

CHESNAIS, F. A mundialização do capital. São Paulo: Xamã, 1996.

CONTINI, E. Exportações na dinâmica do agronegócio brasileiro. In: BUAINAIN, A. M.; ALVES, E.; SILVEIRA, J. M.; NAVARRO, Z. O mundo rural no Brasil do século 21: a formação de um novo padrão agrário e agrícola. Brasília: Embrapa, 2014. p. 147-173.

CPT. COMISSÃO PASTORAL DA TERRA. Caderno de Conflitos no Campo: Brasil 2016. Goiânia: CPT-Nacional, 2016.

DAURA, S. P. Análise do setor de celulose e papel na era da globalização: um olhar sobre sua produção e mão-de-obra. Dissertação (Mestrado em Ciências Sociais) - Faculdade de Filosofia e Ciências, Universidade Estadual Paulista, Marília, 2004.

DE'NADAI, A.; SOARES, L. A.; OVERBEEK, W. Promessas de emprego e destruição de trabalho. In: GOMES, H.; OVERBEEK, W. (Org.). Aracruz credo: 40 anos de violações e resistência no ES. Vitória: Rede Alerta contra o Deserto Verde/Rede Brasil sobre Instituições Financeiras Multilaterais, 2011. p. 107-130.

DELGADO, G. Do capital financeiro na agricultura à economia do agronegócio: mudanças cíclicas em meio século. Porto Alegre: Ed. UFRGS, 2012.

DIEESE. DEPARTAMENTO INTERSINDICAL DE ESTATÍSTICA E ESTUDOS SOCIOECONÔMICOS. O processo de terceirização e seus efeitos sobre os trabalhadores no Brasil. Relatório técnico. São Paulo: Dieese, 2007.

DRUCK, M. G. Trabalho, precarização e resistências: novos e velhos desafios? Caderno CRH, Salvador, v. 24, n. 1, 2011. p. 37-57. 
GONÇALVES, M. T. (Coord.). Pesquisa Expflo: exploração florestal, indústria de celulose e ocupação do espaço regional. Belo Horizonte: Fase/lbase, 1994.

GUDYNAS, E. Estado compensador e nuevos extractivismos: las ambivalencias del progresismo sudamericano. Nueva Sociedad, Buenos Aires, v. 237, p. 128-46, 2012.

HARVEY, D. A produção capitalista do espaço. São Paulo: Annablume, 2005.

IBA. INDÚSTRIA BRASILEIRA DE ÁRVORES. Relatório IBÁ 2015. São Paulo: IBA, 2015. IBGE. INSTITUTO BRASILEIRO DE GEOGRAFIA ESTATÍSTICA. Sidra - Banco de Dados Estatísticos. Disponível em: https://sidra.ibge.gov.br. Acesso em: 25 abr. 2014.

JUVENAL, T. L.; MATTOS, R. L. G. O setor de celulose e papel. In: BNDES. BNDES 50 anos: histórias setoriais, 2002. p. 49-75.

KOOPMANS, J. Além do eucalipto: o papel do Extremo Sul. Teixeira de Freitas, BA: CDDH, 2005.

KRÖGER, M. Globalization as the "Pulping" of Landscapes: Forestry Capitalism's NorthSouth Territorial Accumulation. Globalizations, v. 10, n. 6, p. 837-853, 2013.

KRÖGER, M.; LALANDER, R. Ethnic-territorial rights and the resource extraction boom in Latin America: do constitutions matter? Third World Quarterly, v. 37, n. 4, p. 682-702, 2016.

KUDLAVICZ, M. Dinâmica agrária e a territorialização do complexo celulose/ papel na microrregião de Três Lagoas-MS. Dissertação (Mestrado em Geografia) - CPTL, Universidade Federal de Mato Grosso do Sul, Três Lagoas, 2011.

LEÃO, L. H. C.; VASCONCELLOS, L. C. F. Cadeias produtivas e a vigilância em saúde, trabalho e ambiente. Saúde e Sociedade, São Paulo, v. 24, n. 4, p. 1232-1243, 2015.

LOURENÇO, E. A. Agravos à saúde dos trabalhadores no Brasil: alguns nós críticos. Pegada, Presidente Prudente, v. 12, n. 1, p. 3-33, jun. 2011.

MALINA, L. L. A territorialização do monopólio no setor celulístico-papeleiro: a atuação da Veracel Celulose no extremo sul da Bahia. Dissertação (Mestrado em Geografia) - Faculdade de Filosofia, Letras e Ciências Humanas, Universidade de São Paulo, São Paulo, 2013.

MARINI, R. M. Dialética da dependência, 1973. In: TRASPADINI, R.; STEDILE, J. P. (Org.).

Ruy Mauro Marini: vida e obra. São Paulo: Expressão Popular, 2011. p. 137-180.

MARX, K. O capital: crítica da economia política (Livro 1 - processo de produção do capital). São Paulo: Boitempo, 2013. Livro 1: Processo de produção do capital.

MARX, K. O 18 de brumário de Luís Bonaparte. São Paulo: Boitempo, 2011.

MARX, K. Miséria da filosofia: resposta à filosofia da miséria, do Sr. Proudhon. São Paulo: Expressão Popular, 2009. 
MATtOSO, J. E. L. A desordem do trabalho. São Paulo: Página Aberta, 1995.

MÉSZÁROS, I. Para além do capital: rumo a uma teoria da transição. São Paulo: Boitempo, 2011.

MÉSZÁROS, I. O desafio e o fardo do tempo histórico: o socialismo no século XXI. São Paulo: Boitempo, 2007.

MILANEZ, B. Mineração e impactos socioambientais: as dores de um país extrativista. Juiz de Fora, 2016. Não publicado.

MORELLI, L. A. A monocultura do eucalipto e a monopolização do território na metade sul do Rio Grande do Sul. Tese (Doutorado em Geografia Ambiental) - Instituto de Geociências, Universidade Federal do Rio Grande do Sul, Porto Alegre, 2011.

OBSERVATÓRIO DIGITAL DE SAÚDE E SEGURANÇA DO TRABALHO. [2017?]. Disponível em: https://observatoriosst.mpt.mp.br/. Acesso em: 25 abr. 2014.

O EUCALIPTO não alimenta ninguém. CPT. COMISSÃO PASTORAL DA TERRA. Goiânia, 11 dez. 2012. Disponível em: http://www.cptnacional.org.br/index.php/publicacoes/noticias/geral/1379-o-eucalipto-naoalimenta-ninguem. Acesso em: 25 abr. 2014.

OLIVEIRA, A. L. A. Aspectos da dinâmica socioterritorial do trabalho terceirizado: em busca dos "territórios terceirizados". Dissertação (Mestrado em Geografia) - Universidade Federal de Mato Grosso do Sul, Três Lagoas, 2014.

OVERBEEK, W.; KRÖGER, M.; GERBER, J.-F. Um panorama das plantações industriais de árvores no sul global: conflitos, tendências e lutas de resistência. Relatório Ejolt, n. 3, 2012.

PAKKASVIRTA, J. Fábricas de celulosa: historias de la globalización. Buenos Aires: La Colmena, 2010.

PEDREIRA, M. S. O complexo florestal e o extremo sul da Bahia: inserção competitiva e transformações socioeconômicas na região. Tese (Doutorado em Ciências Sociais em Desenvolvimento, Agricultura e Sociedade) - Universidade Federal Rural do Rio de Janeiro, Rio de Janeiro, 2008.

PERPETUA, G. M. Pilhagem territorial, precarização do trabalho e degradação do sujeito que trabalha: a territorialização do capital arbóreo-celulósico no Brasil contemporâneo. Tese (Doutorado em Geografia) - Faculdade de Ciências e Tecnologia, Universidade Estadual Paulista, Presidente Prudente, 2016.

PERPETUA, G. M. A miragem verde: um olhar sobre a mobilidade espacial do capital e da força de trabalho a partir de Três Lagoas (MS, Brasil). Saarbrücken, DE: Novas Edições Acadêmicas, 2013. 
PERPETUA, G. M.; GONÇALVES, R. J. G. A expansão territorial das commodities agrominerais e a questão do desenvolvimento regional no Brasil: algumas notas preambulares. In: RIBEIRO SILVA, C. H. (Org.). O despertar regional: diálogos entre geografia(s) e desenvolvimento regional de Mato Grosso do Sul. Saarbrücken, DE: NEA, 2017. v. 2. p. 39-53.

PERPETUA, G. M.; THOMAZ JUNIOR, A. O hibridismo entre Estado e capital na constituição e expansão territorial do monocultivo do eucalipto e da produção de celulose no Brasil. In: RAMOS FILHO, E. S.; FELICIANO, C. A. (Org.). Políticas públicas de desenvolvimento e apropriação da natureza: terra, água e conflitos socioterritoriais. São Paulo: Outras Expressões, 2019. No prelo.

PERPETUA, G. M.; THOMAZ JUNIOR, A. Desconstruindo o discurso de legitimação da produção brasileira de commodities agrominerais a partir da celulose. Sapiência: Sociedade, Saberes e Práticas Educacionais, Iporá: UEG, v. 5, n.1, p. 57-74, jan./jul. 2016.

PERPETUA, G. M.; THOMAZ JUNIOR, A. Dinâmica geográfica da mobilidade do capital na produção de celulose e papel em Três Lagoas (MS). Revista da ANPEGE, vol. 9 , n. 12, p. 55-69, jul./dez. 2013.

PETRAS, J. Brasil: o capitalismo extrativo e o grande salto para trás. Tensões Mundiais, Fortaleza, v. 10, n. 18-19, p. 301-324, 2014.

PORTO-GONÇALVES, C. W. Geografia da riqueza, fome e meio ambiente: pequena contribuição crítica ao atual modelo agrário/agrícola de uso dos recursos naturais. In: OLIVEIRA, A. U.; MARQUES, M. I. M. (Org.). O campo no século XXI. São Paulo: Casa Amarela/Paz e Terra, 2004. p. 207-254.

RIBEIRO JUNIOR, J. A. S. O desenvolvimento geográfico desigual da Suzano Papel e Celulose no Maranhão. Dissertação (Mestrado em Geografia Humana) Faculdade de Filosofia, Letras e Ciências Humanas, Universidade de São Paulo, São Paulo, 2014.

SANTOS, J. R. A constituição do complexo agroindustrial de celulose no Rio Grande do Sul: uma avaliação da dinâmica global e da inserção brasileira no setor. In: ENCUENTRO DE GEÓGRAFOS DE AMÉRICA LATINA, 12., 2009, Montevideo. Annales... Montevideo, 2009.

SICSÚ, J.; PAULA, L. F; MICHEL, R. Por que novo-desenvolvimentismo? Revista de Economia Política, São Paulo, v. 27, n. 4, p. 507-524, out./dez. 2007.

SILVA, C. H. R. Política industrial brasileira e a industrialização de Mato Grosso do Sul no século XXI. Tese (Doutorado em Geografia) - Faculdade de Ciências Humanas, Universidade Federal da Grande Dourados, Dourados, MS, 2016.

SILVA, M. et al. Panorama em segurança e saúde no trabalho (SST) na indústria: Brasil e unidades da federação 2004: setor químico (CNAE 24). Brasilia, DF: SESI; DN, 2011. 
SMITH, N. Desenvolvimento desigual. Rio de Janeiro: Bertrand, 1988.

SOUZA, I. G.; OVERBEEK, W. (Org.). Violações socioambientais promovidas pela Veracel Celulose, propriedade da Stora Enso e da Aracruz Celulose: uma história de ilegalidades, descaso e ganância. São Paulo: Expressão Popular, 2008.

THOMAZ JUNIOR, A. Os desafios rumo a um projeto para o Brasil! (Intemperismo do trabalho e as disputas territoriais contemporâneas). Revista da Anpege, São Paulo, v. 7 , n. 1, p. 307-329, 2012.

VILELA, A. G.; IGUTI, A. M.; ALMEIDA, I. M. Culpa da vítima: um modelo para perpetuar a impunidade nos acidentes de trabalho. Cadernos de Saúde Pública, Rio de Janeiro, v. 20, n. 2, p. 570-579, mar./abr. 2004. 